\title{
A Review of Diagnostic Impact of Amyloid Positron Emission Tomography Imaging in Clinical Practice
}

\author{
Yejin Kim ${ }^{a}$ Paul Rosenberg ${ }^{c}$ Esther Oh ${ }^{b-d}$ \\ a Johns Hopkins Bloomberg School of Public Health, Baltimore, MD, USA; b Department of \\ Medicine, Johns Hopkins University School of Medicine, Baltimore, MD, USA; ${ }^{\circ}$ Department \\ of Psychiatry and Behavioral Sciences, Johns Hopkins University School of Medicine, \\ Baltimore, MD, USA; ${ }^{d}$ Department of Pathology, Johns Hopkins University School of \\ Medicine, Baltimore, MD, USA
}

\section{Keywords}

Amyloid · Alzheimer's disease · Biomarkers · Dementia - Mild cognitive impairment · Positron emission tomography

\begin{abstract}
Background: Molecular imaging of brain amyloid for the diagnosis of Alzheimer's disease (AD) using positron emission tomography (PET) has been approved for use in clinical practice by the Food and Drug Administration (FDA) since 2012. However, the clinical utility and diagnostic impact of amyloid PET imaging remain controversial. We conducted a review of the recent studies investigating clinical utility of amyloid PET imaging with focus on changes in diagnosis, diagnostic confidence, and patient management. Summary: A total of 16 studies were included in the final analysis. Overall rate of changes in diagnosis after amyloid PET ranged from 9 to $68 \%$ (pooled estimate of $31 \%, 95 \% \mathrm{Cl} 23-39 \%$ ). All studies reported overall increase in diagnostic confidence or diagnostic certainty after amyloid PET. Changes in patient management ranged from 37 to $87 \%$; the most common type of change in management reported was either the initiation or discontinuation of planned AD medications. Key Messages: Amyloid PET imaging led to moderate to significant changes in diagnosis, diagnostic confidence, and subsequent patient management. It may be most useful in patients with high level of diagnostic uncertainty even after the completing the standard workup.
\end{abstract}


Kim et al.: Utility of Amyloid PET Imaging

\section{Introduction}

Alzheimer's disease (AD) is a neurodegenerative disorder characterized by gradual cognitive decline which progressively worsens over time. AD is the most common form of dementia in the US which is estimated to affect 5.5 million individuals [1] and is also the sixth leading cause of mortality in the US $[1,2]$. Despite the increased incidence and mortality associated with $\mathrm{AD}$, there is still no effective disease-modifying treatment available. Therefore, there has been increased interest in interventions that target earlier stages of AD [3] such as preclinical or mild cognitive impairment (MCI) stages. However, accurate diagnosis of AD in the earlier stages still remains a challenging task for physicians. AD biomarkers have become an integral part of clinical trials as they are useful in identifying individuals who may benefit most from a potential therapeutic intervention. In addition, since the publication of the National Institute on Aging-Alzheimer's Association (NIA/AA) working group's recommendations to incorporate biomarkers to improve diagnostic confidence [4], there have been additional efforts to integrate biomarkers into clinical practice.

Various biomarkers which target different AD stages and pathological processes have been developed over the past years. Currently, there are two major types of biomarkers: fluidbased biomarkers and imaging biomarkers. Examples of fluid-based biomarkers include cerebrospinal fluid (CSF) measures of amyloid-beta as well as total tau and phosphorylated tau; these biomarkers represent two pathological hallmarks of $\mathrm{AD}$, amyloid plaques and neurofibrillary tangles, respectively. Imaging biomarkers include magnetic resonance imaging (MRI) examining brain structure, fluoro-deoxy-glucose positron emission tomography (FDG-PET) measuring the rate of glucose uptake in cortical neurons and glial cells, and more recently amyloid PET which measures the level of amyloid burden in the brain [5].

The first amyloid PET tracer to be widely studied in humans is a ${ }^{11} \mathrm{C}$-Pittsburgh compound $\mathrm{B}(\mathrm{PiB})$ which has been well-validated for quantifying the brain amyloid burden and has been used in clinical research since 2004 [6, 7]. However, the short half-life $(20 \mathrm{~min})$ of ${ }^{11} \mathrm{C}$ limited its use in routine clinical settings [8]. This shortcoming has been addressed by ${ }^{18} \mathrm{~F}$-labeled radiotracers with a longer half-life $(110 \mathrm{~min})$. Several ${ }^{18} \mathrm{~F}$ amyloid ligands have been developed, including ${ }^{18} \mathrm{~F}$-florbetapir (Amyvid ${ }^{\mathrm{TM}}$ ), ${ }^{18} \mathrm{~F}$-flutemetamol (Vizamyl $^{\mathrm{TM}}$ ), 3'F-PiB or GE-067, ${ }^{18}$ F-florbetaben (Neuraceq ${ }^{\mathrm{TM}}$; also called BAY94-9172 or AV-1), and ${ }^{18} \mathrm{~F}-\mathrm{NAV} 4694$ (formerly AZD4694) [9]. At the present time, ${ }^{18} \mathrm{~F}$-labeled ligands ${ }^{18} \mathrm{~F}$-florbetapir, ${ }^{18} \mathrm{~F}$-flutemetamol, and ${ }^{18} \mathrm{~F}$-florbetaben have been approved for use in clinical settings by the US Food and Drug Administration (FDA) [10].

The appropriate use criteria (AUC), established by the Alzheimer's Association and the Society of Nuclear Medicine and Molecular Imaging with a group of imaging and dementia specialists, is a set of criteria for clinical scenarios in which the use of amyloid PET would be most appropriate [11]. The three clinical indications for the use of amyloid PET imaging outlined by AUC include the following: (1) patients with progressive MCI in which clinical uncertainty exists and the patient would benefit from greater certainty; (2) patients with dementia syndrome suggestive of AD, but with an atypical presentation or suspected mixed etiology; and (3) patients with early-onset progressive cognitive decline. However, these criteria limited the use of amyloid PET to cases involving a significant clinical uncertainty, assuming that amyloid PET would be of less added value in patients with typical AD. A major issue with amyloid imaging is whether there is sufficient evidence for the clinical utility and cost-effectiveness of amyloid PET for diagnosis or treatment of dementia or neurodegenerative disease. Due to this reason, the Centers for Medicare and Medicaid Services (CMS) does not currently reimburse amyloid PET for Medicare beneficiaries [12].

In response to this decision of by CMS in 2013, a 4-year, large-scale study called "Imaging Dementia-Evidence for Amyloid Scanning (IDEAS)" was initiated by the Alzheimer's Associ- 
ation and other interested stakeholders including the American College of Radiology (ACR). The aim of the IDEAS study, which was approved by the CMS in 2015, is to compile evidence on the utility and clinical impact of amyloid PET in diagnosis, diagnostic confidence, and patient management of cognitively impaired patients with a diagnostic uncertainty for those who meet the AUC. IDEAS study started enrollment in February of 2016, and completed enrollment of 18,488 Medicare beneficiaries older than 65 years of age in December 2017 [13]. The evidence gained will most likely impact on future insurance reimbursement of amyloid PET.

The goal of this review is to examine published data reflecting the clinical utility of amyloid PET with the most widely investigated radiotracer ${ }^{11} \mathrm{C}-\mathrm{PiB}$ and the three FDAapproved ${ }^{18} \mathrm{~F}$-labeled ligands $\left({ }^{18} \mathrm{~F}\right.$-florbetaben, ${ }^{18} \mathrm{~F}$-flutemetamol, and ${ }^{18} \mathrm{~F}$-florbetapir). This review will focus on the utility of amyloid PET for clinical outcomes including diagnostic decision making process (changes in diagnosis after the scan and diagnostic confidence) as well as how scan results change the clinical management of patients. This review will take a broader perspective of amyloid PET use, including studies that examined amyloid PET in different countries, in individuals who are younger ( $<65$ years of age) as well as in those who may not meet the AUC.

\section{Methods}

Search Strategy and Study Selection

Relevant studies were identified through electronic searches, which were performed in PubMed, EMBASE, and SCOPUS, for eligible studies published from January 2012 through May 2018. The search strategy was performed with a combination of terms for titles, abstracts, and keywords (see online suppl. Table e-1; for all online suppl. material, see www.karger.com/doi/10.1159/000492151). The title and abstract of each article were initially screened by Y.K., and the full texts were reviewed for eligibility criteria by two reviewers (Y.K. and E.O.). If there were disagreements regarding eligibility, consensus was derived by discussion. The inclusion criteria of this study were as follows: (1) studies that used amyloid-PET as part of a diagnostic workup; (2) studies that included $\geq 10$ subjects; (3) outcome measures included changes in diagnosis, diagnostic confidence, and/or patient management; (4) studies that were published as peer-reviewed journal articles. Studies were excluded if the studies were (1) not written in English language, (2) did not include data on clinical utility of amyloid-PET, (3) nonhuman studies. Flow diagram of the search strategy and reasons for exclusion are listed on online Supplementary e-Figure 1. Reference lists of retrieved articles were also screened to ensure all relevant studies were included.

\section{Data Collection and Statistics}

Data collection was performed by two reviewers (Y.K. and E.O.) using a data extraction form specifically designed for the study. Extracted data included author, year, participant characteristics, information on diagnostic procedure, and changes in diagnosis, diagnostic confidence, and patient management. For change in diagnosis, a meta-analysis was performed to fit a random-effects model with a random intercept for study, resulting in an estimate that accounts for both the varying size of each study and any possible correlation among observations within studies.

\section{Results}

\section{Search Results}

Literature search yielded 805 titles and abstracts (see online suppl. e-Fig. 1). After removing duplicates, a total of 644 titles and abstracts were retrieved and further reviewed for eligibility. A total of 16 studies were included in this review after eliminating articles that did not meet inclusion/exclusion criteria. 


\section{Study Characteristics}

Table 1 shows the characteristics and the main findings of the included studies. Five studies were conducted in the US [7, 14, 15], 2 studies in the UK [16, 17], 2 in Netherlands [18, 19], and 1 each in Italy [10], Canada [20], France [21], and Denmark [22]. Two studies were multicenter studies with one study conducted in Australia, Germany, Japan, Switzerland, and USA [23], and the other in France, Italy, and USA [24]. ${ }^{18} \mathrm{~F}$ radiotracers $\left({ }^{18} \mathrm{~F}\right.$-florbetapir, ${ }^{18} \mathrm{~F}$-florbetaben, ${ }^{18} \mathrm{~F}$-flutemetamol, and ${ }^{18} \mathrm{~F}$-NAV4694) were used in 13 out of 16 studies (Table 1), and the remaining 3 studies used ${ }^{11} \mathrm{C}$-PiB as the study ligand (Table 2). Amyloid scan results were interpreted visually in all studies; 2 studies used both visual and quantitative interpretation methods with the mean standard uptake value ratios of 1.17 [14] and 1.50 [20] as the quantitative cutoff for amyloid positivity (Table 3).

\section{Change in Diagnosis}

The overall rate of the change in prescan to postscan diagnosis ranged from 9 to $68 \%$ (pooled estimate of 31\%, 95\% CI 23-39\%). In cases where prescan diagnosis was AD, the rate of change in diagnosis ranged from 13 to $37 \%$ [10, 15, 18-20,25, 26]. When prescan diagnosis was non-AD etiology, diagnostic change ranged from 14 to $62 \%[10,18-20,26]$. Changes in diagnosis were made in up to $66 \%$ of the cases for those with prescan diagnosis of uncertain or indeterminate etiology $[22,25,26]$. In 3 studies that examined diagnostic change in MCI, very few diagnostic changes were made after the disclosure of amyloid PET results $[15,16$, $18,25]$.

Two studies categorized individuals by those who met the AUC and those who did not. One study reported significantly higher rate of diagnostic change in the AUC group compared to the non-AUC group (62 vs. $45 \%, p=0.01$ ) [27]. Similarly, another study reported higher rate of diagnostic change in the AUC group compared to the non-AUC group (53 vs. 23\%), but this difference was not statistically significant [14]. In cases where the amyloid-PET scans were positive, the rate of change in diagnosis ranged from 11 to $52 \%[7,19,22,26]$. In cases where the amyloid-PET scans were negative, the rate of change in diagnosis ranged from 7 to $57 \%[7,19,22,26]$. In $90-99 \%$ of those with amyloid-positive scans, the diagnosis of AD etiology was finalized, and $87-99 \%$ of those with amyloid-negative scans received the final diagnosis other than AD etiology $[10,26]$. Those who obtained negative amyloid PET scan with previous diagnosis of $\mathrm{AD}$ were likely to have a diagnostic change to other disorders including dementia with Lewy bodies, corticobasal degeneration, cerebrovascular dementia (CVD), and frontotemporal lobar degeneration, depression, or dementia due to undetermined etiology $[18,25]$. The majority of patients with previous clinical diagnosis of non-AD with positive scan were given postscan diagnosis of AD [10] (Table 1).

\section{Change in Diagnostic Confidence}

Change in diagnostic confidence was also examined in 10 studies, and all reported overall increase in diagnostic confidence or diagnostic certainty following disclosure of PET imaging $[17-23,25]$. In a subset the study population, diagnostic confidence decreased when diagnosis changed from prescan diagnosis of $\mathrm{AD}$ to non-AD after a negative amyloid-PET [10, 19, 23] (Table 1).

\section{Change in Patient Management and Treatment}

Overall change in patient management ranged from 37 to $87 \%$ [16, 19-21, 24, 26, 27]. The most common type of change in management was either the initiation or discontinuation of planned AD medication such as memantine or cholinesterase inhibitors which ranged from 20 to $60 \%$ of the overall study populations $[7,10,16,19,21,26,27]$. Other types of management changes included referral to clinical trials, AD genetic testing [17], additional diagnostic tests 
Dementia

and Geriatric
Cognitive Disorders
Dement Geriatr Cogn Disord 2018;46:154-167

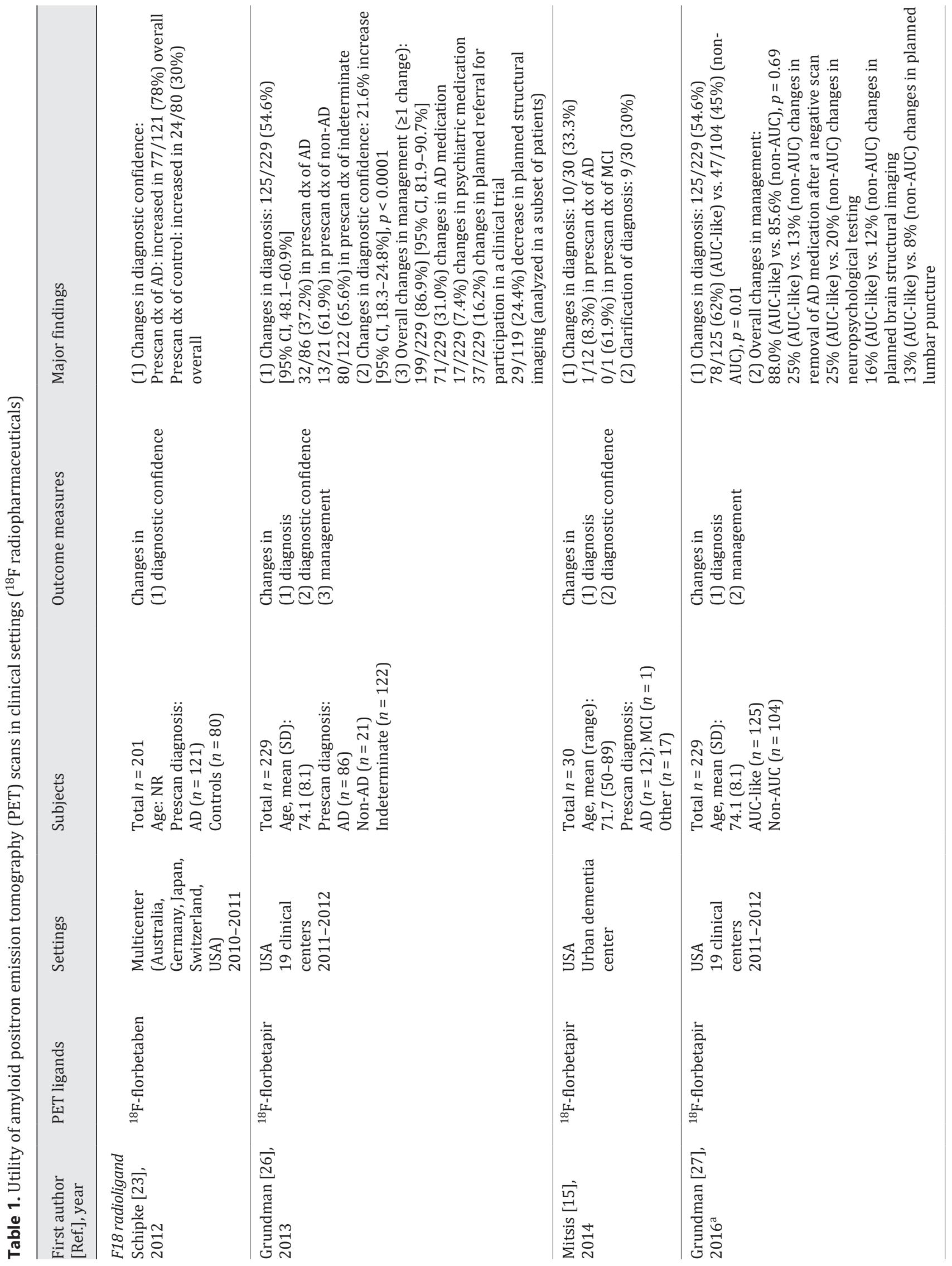


Dementia

and Geriatric
Cognitive Disorders
Dement Geriatr Cogn Disord 2018;46:154-167

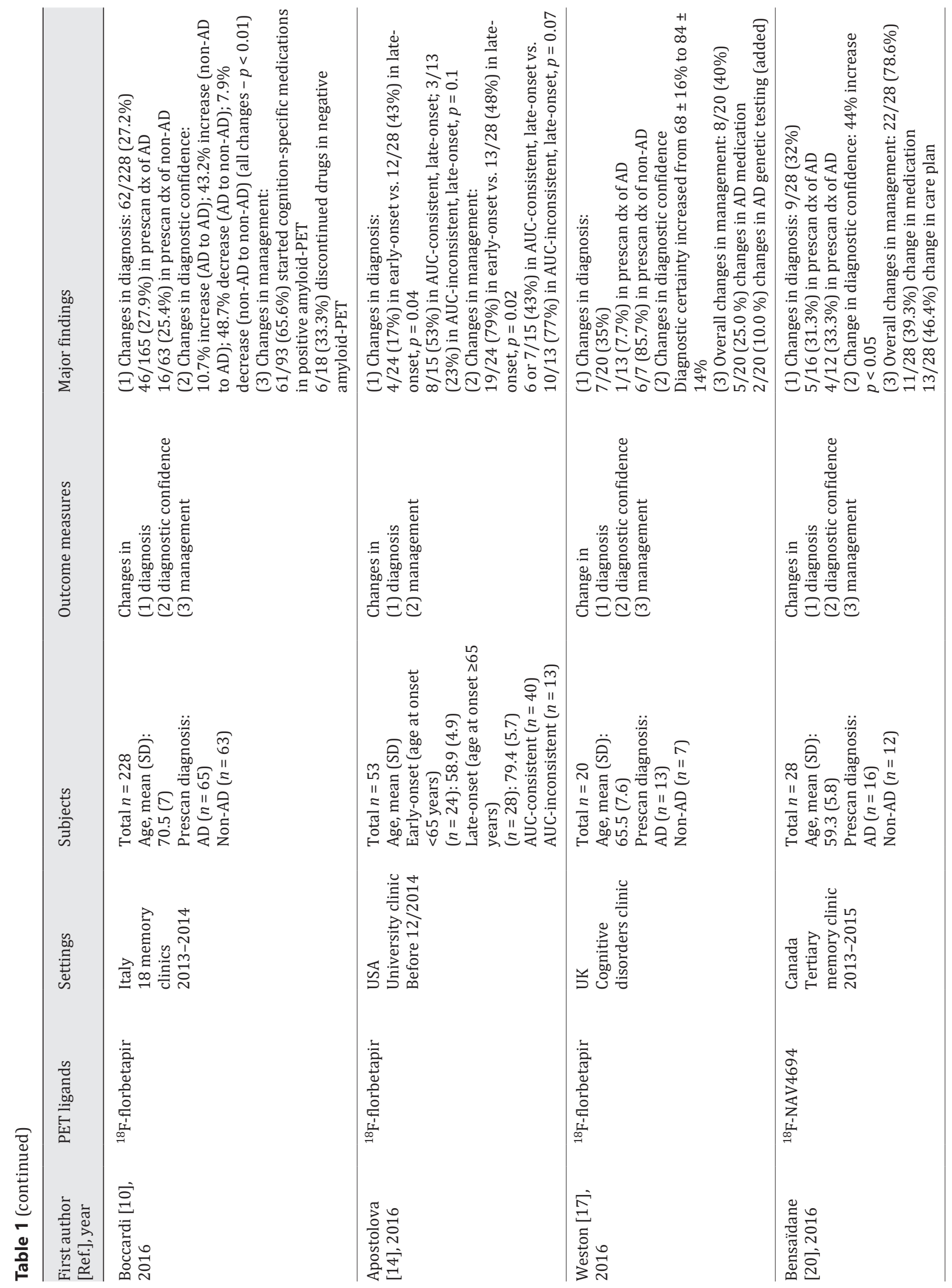


Dementia

and Geriatric
Cognitive Disorders
Dement Geriatr Cogn Disord 2018;46:154-167
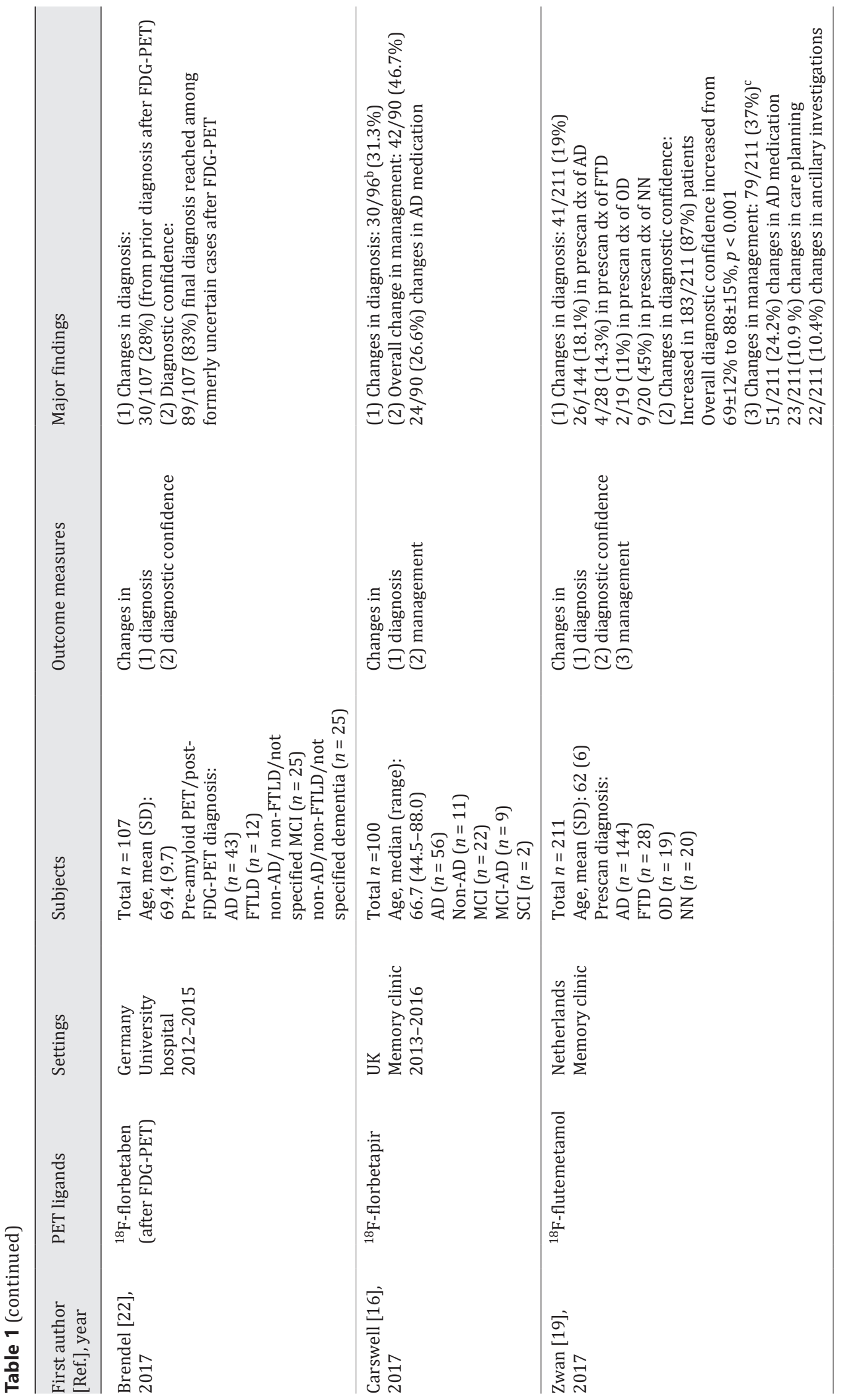
Dementia

and Geriatric
Cognitive Disorders
Dement Geriatr Cogn Disord 2018;46:154-167

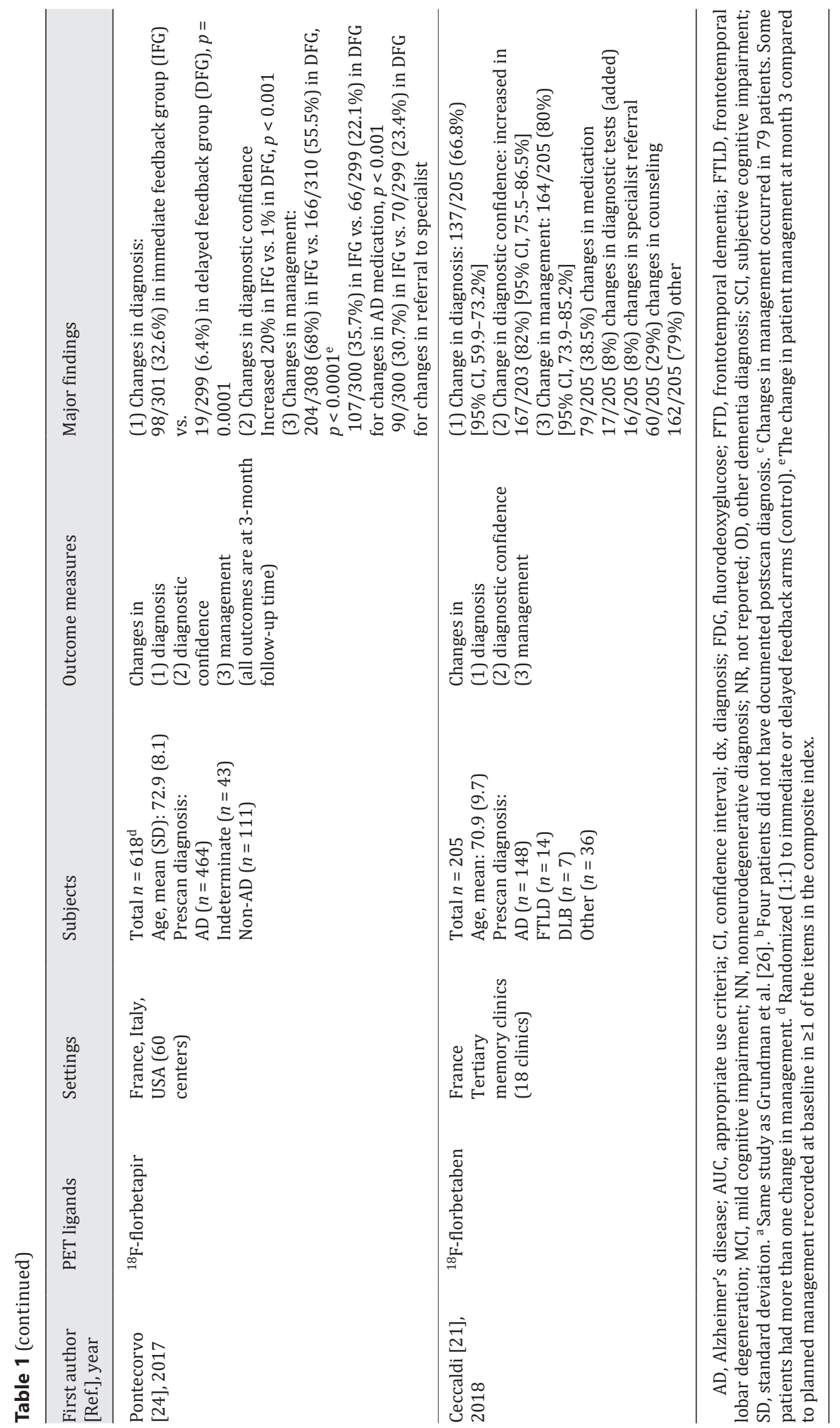


Dementia

and Geriatric
Cognitive Disorders
Dement Geriatr Cogn Disord 2018;46:154-167

\begin{tabular}{l|l|l}
\hline DOI: 10.1159/000492151 & ( 2018 S. Karger AG, Basel \\
\hline
\end{tabular}

www.karger.com/dem

Kim et al.: Utility of Amyloid PET Imaging

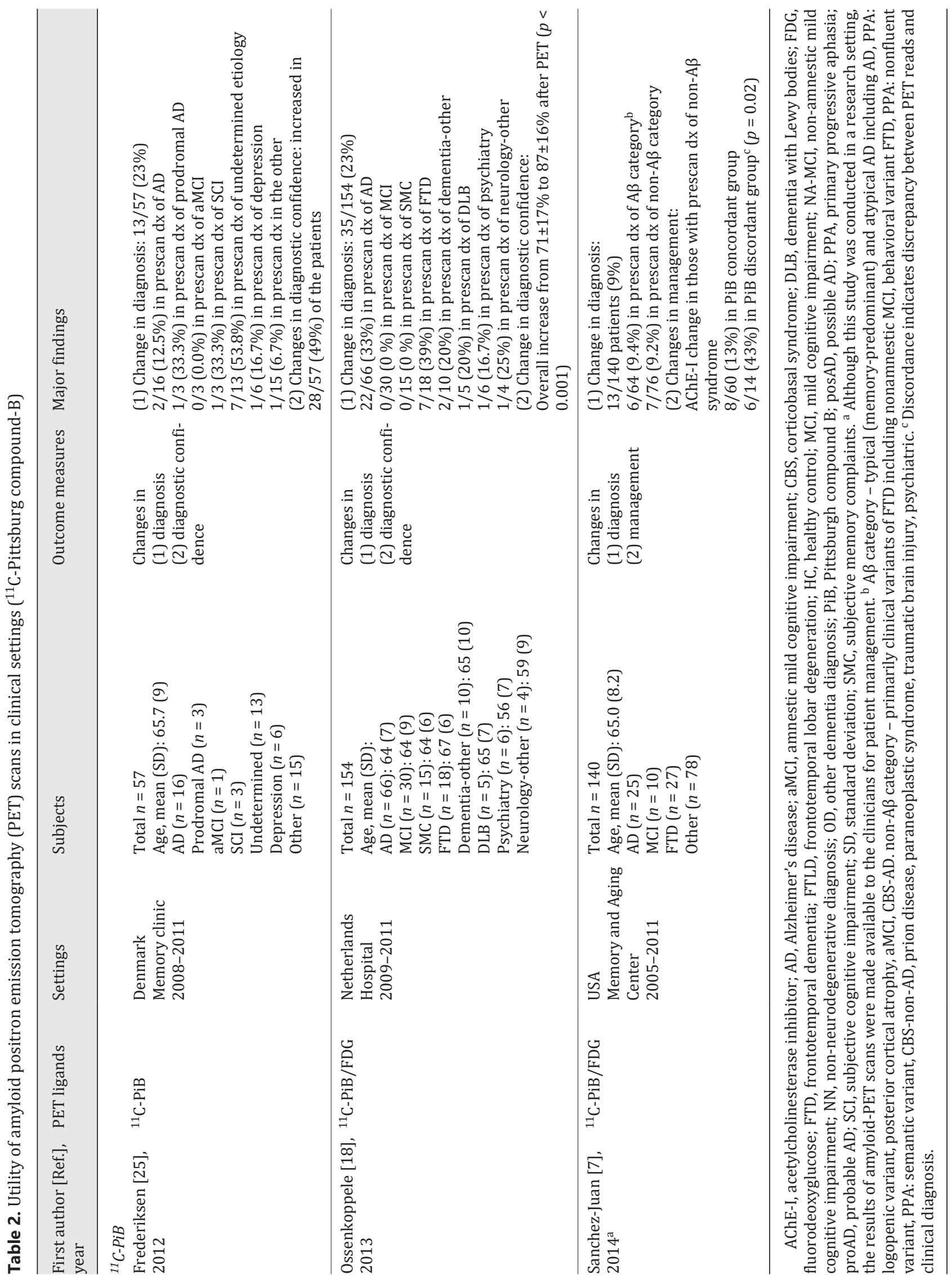


Table 3. Evaluation of amyloid-PET results

\begin{tabular}{|c|c|c|c|c|c|c|c|}
\hline \multirow[t]{2}{*}{ First author [Ref.], year } & \multirow[t]{2}{*}{ PET ligand } & \multirow[t]{2}{*}{$\begin{array}{l}\text { Image } \\
\text { analysis }\end{array}$} & \multicolumn{2}{|c|}{ Qualitative assessment } & \multicolumn{2}{|c|}{$\begin{array}{l}\text { Quantitative } \\
\text { assessment }\end{array}$} & \multirow[t]{2}{*}{$\begin{array}{l}\text { Reference } \\
\text { region }\end{array}$} \\
\hline & & & $\begin{array}{l}\text { image } \\
\text { analysis }\end{array}$ & $\begin{array}{l}\text { interrater } \\
\text { reliability }\end{array}$ & method & $\begin{array}{l}\text { cutoff } \\
\text { value, AUC }\end{array}$ & \\
\hline Schipke [23], 2012 & ${ }^{18} \mathrm{~F}$-florbetaben & NR & NR & NR & NR & NR & NR \\
\hline Grundman [26], 2013 & ${ }^{18} \mathrm{~F}$-florbetapir & visual & binary & NA & NA & NA & NR \\
\hline Mitsis [15], 2014 & ${ }^{18} \mathrm{~F}$-florbetapir & visual & binary & NR & NA & NA & $\begin{array}{l}\text { cerebral gray } \\
\text { matter }\end{array}$ \\
\hline Grundman [27], 2016 & ${ }^{18} \mathrm{~F}$-florbetapir & visual & binary & NA & NA & NA & NR \\
\hline Bocardi [10], 2016 & ${ }^{18} \mathrm{~F}$-florbetapir & visual $^{\mathrm{a}}$ & binary & $\begin{array}{l}\kappa=0.74 \\
S E, 0.042\end{array}$ & NA & NA & NR \\
\hline Apostolova [14], 2016 & ${ }^{18} \mathrm{~F}$-florbetapir & $\begin{array}{l}\text { visual, } \\
\text { quantitative }\end{array}$ & binary & NR & SUVR $^{\mathrm{b}}$ & 1.17 & $\begin{array}{l}\text { whole } \\
\text { cerebellum }\end{array}$ \\
\hline Weston [17], 2016 & ${ }^{18} \mathrm{~F}$-florbetapir & visual & binary & NR & NR & NR & NR \\
\hline Bensaidane [20], 2016 & ${ }^{18} \mathrm{~F}-\mathrm{NAV} 4694$ & $\begin{array}{l}\text { visual, } \\
\text { quantitative }\end{array}$ & binary & NR & SUVR & 1.50 & $\begin{array}{l}\text { cerebellar } \\
\text { cortex }\end{array}$ \\
\hline Brendel [22], 2017 & ${ }^{18} \mathrm{~F}$-florbetaben & visual & binary & NR & NA & NA & NR \\
\hline Carswell [16], 2017 & ${ }^{18} \mathrm{~F}$-florbetapir & visual & binary & NR & NA & NA & NR \\
\hline Pontecorvo [24], 2017 & ${ }^{18} \mathrm{~F}$-florbetapir & visual & binary & NA & NA & NA & NR \\
\hline Zwan [19], 2017 & ${ }^{18} \mathrm{~F}$-flutemetamol & visual & binary & NR & NA & NA & NR \\
\hline Ceccaldi [21], 2017 & ${ }^{18} \mathrm{~F}$-florbetaben & visual & binary & NR & NA & NA & NR \\
\hline Frederiksen [25], 2012 & ${ }^{11} \mathrm{C}-\mathrm{PiB}$ & visual & binary & NR & NA & NA & white matter \\
\hline Ossenkoppele [18], 2013 & ${ }^{11} \mathrm{C}-\mathrm{PiB}$ & visual & binary & NR & NA & NA & $\begin{array}{l}\text { cerebellar } \\
\text { gray matter }\end{array}$ \\
\hline Sanchez-Juan [7], 2014 & ${ }^{11} \mathrm{C}-\mathrm{PiB}$ & visual & binary & NR & NA & NA & cerebellum \\
\hline
\end{tabular}

AUC, area under the curve; NA, not applicable; NR, not reported; PiB, Pittsburgh compound B; SUVR, standard uptake value ratio. a 267 amyloid PET scans by two readers, and 15 cases read by a reference expert from the ligand manufacturer. ${ }^{b}$ SUVR estimated in the context of the publication; 1 positive clinical read with a normal SUVR $=0.94 ; 5$ negative clinical reads with a positive SUVR from 1.30 to 1.44 attributed to poor scan quality or possible late acquisition and brain atrophy.

[21], or starting depression treatment $[16,26]$. A significant reduction in additional investigations was noted in 2 studies. One study reported $24 \%$ decrease in plans for structural imaging after amyloid pathology was confirmed by amyloid PET [26]; another study showed that the number of investigations (e.g., MRI or CT head, DaTscan or FDG-PET, CSF analysis, neuropsychological assessment, and genetic blood tests) decreased after amyloid PET became available compared to a prior time period [16].

When the AUC was applied, overall change in management was slightly higher in the AUC group compared to the non-AUC group in one study, but the difference was statistically not significant (88 vs. $86 \%, p=0.69$ ) [27]. Another study also did not find significant differences in change in management between the AUC and the non-AUC groups [14] (Table 1).

\section{Discussion}

The goal of this review article was to provide overview of the clinical utility of amyloid PET including diagnosis, diagnostic confidence, and patient management. The rate of change in diagnosis differed based on several factors including the patient demographics, complexity of the patient population, prescan diagnosis, and whether or not the patients met the AUC criteria. Some studies examined patients who presented with diagnostic uncertainty with 
Dementia

and Geriatric
Cognitive Disorders \begin{tabular}{l|l}
\hline Dement Geriatr Cogn Disord 2018;46:154-167 \\
\hline DOI: 10.1159/000492151 & $\begin{array}{l}\text { @ 2018 S. Karger AG, Basel } \\
\text { www.karger.com/dem }\end{array}$ \\
\hline
\end{tabular}

Kim et al.: Utility of Amyloid PET Imaging

atypical presentation or early-onset features $[16,17,26]$, while others examined all-comers $[7,10,15,18,25]$. Studies that limited the use of amyloid-PET to those with atypical presentation or early-onset features had a higher rate of change in diagnosis compared to the studies that included all-comers. The higher rate of change in diagnosis suggests that amyloid PET is more useful for patients with high level of diagnostic uncertainty even after completing the standard workup [18].

Among the studies that were included in our review, diagnostic changes were uncommon when the prescan diagnosis was MCI. However, they were based on a small number of individuals $[16,18,25]$. Most recent report from the interim analysis of the IDEAS study which had a large number of individuals with $\mathrm{MCI}$ diagnosis showed that changes in diagnosis were seen in a large proportion of the MCIs [28]. Additional utility of amyloid PET in MCI is reflected in the interim analysis of the IDEAS study which showed that changes in medical management were seen in $67.8 \%$ of MCI patients. Changes in medical management consisted of $47.8 \%$ change in AD drugs, $36.0 \%$ in non-AD drugs, and $23.9 \%$ changes in counseling [28].

Elevated amyloid deposition in MCI is associated with greater cognitive decline over time [29]. Despite the low rate of diagnostic change in MCI in the studies included in this review, it is important to take into consideration that amyloid PET reveals critical information for identifying individuals who are at high risk for disease progression [30]. Current AUC identifies MCI patients with clinical uncertainty as a group in which amyloid PET would be clinically useful [11], and MCI patients with high amyloid burden should be closely monitored [31].

Amyloid PET had considerable impact on change in treatment and management plan. The most common change reported was either an initiation of drug therapy with acetylcholinesterase inhibitors (AChEIs) or memantine, or discontinuation of previously prescribed medication. Currently, the existing therapeutic options are limited to symptomatic and not diseasemodifying treatments $[10,32]$. However, even with the lack of disease-modifying therapy for $\mathrm{AD}$, amyloid PET still adds value to the management of patients by improving diagnostic confidence and clarifying diagnostic dilemmas [33]. It will help minimize misdiagnosis of patients, and also minimize adverse events due to potentially inappropriate treatment of patients as in the case of AChEI use in frontotemporal lobar degeneration patients [34-36]. Nevertheless, it is important to note that in one recent randomized control trial examining the impact of amyloid PET on patient management, AChEI use did not change significantly in subjects with negative amyloid PET [24].

Another notable change in management was the reduction of additional diagnostic tests (e.g., FDG-PET, structural imaging, neuropsychological tests). In some studies, planned structural imaging, a routine part of dementia workup, was eliminated in a substantial proportion of patients, regardless of amyloid positivity [16, 26, 27]. Removal of additional testing from the patient's management plan may in part demonstrate that clinicians viewed amyloid status as offering adequate information, especially in patients with mild cases of cognitive impairment where additional testing may not yield much more information (e.g., borderline or negative FDG-PET, psychometric testing) [26]. However, one of the studies that had autopsy results from a subgroup of patients showed that 2 patients who had positive amyloid PET had primary frontotemporal dementia pathology along with copathology of AD [7]. Therefore, more caution needs to be exercised in relying heavily on amyloid PET results in clinical diagnosis [7]. The IDEAS study may answer the question of whether revised clinical workup brought about by disclosure of amyloid PET results actually translates into a better clinical outcome [13].

Two studies extensively reviewed the impact of Appropriate Use Criteria (AUC) [14, 27]. In both studies, the rates of diagnostic change following the disclosure of amyloid PET results were reported to be higher in the AUC groups, which tended to include a larger number of 
patients with diagnosis of atypical or non-AD etiology compared to the non-AUC groups. However, in terms of patient management the overall rate of change in management was comparable or even higher in the non-AUC group compared to AUC group in both studies [14, 27]. This may be partly due to how each study defined as change in patient management, as one of the studies included counseling about diagnosis and addressing potential safety concerns as part of the patient management [27]. These types of patient care activities would most likely apply equally to both AUC and non-AUC groups. Considering a greater incremental value of amyloid imaging in subjects with significant diagnostic uncertainty, AUC seem to be useful in determining what types of patients may benefit from amyloid PET in terms of clarifying diagnosis. Nevertheless, the high rates of change in treatment and management plans in patients who did not meet the strict definition of the criteria for AUC may imply that amyloid PET imaging may provide equally helpful piece of information for the non-AUC group of patients as well. Further examination of different categories of patient management and longitudinal outcome assessment of changes in management will inform the most effective use of amyloid PET.

The present review has several limitations. First, these are essentially studies of clinician behavior in response to amyloid PET results. Clinician bias might have affected the results due to the real-world, observational nature of these studies. Second, there are few data on clinicopathological correlations of amyloid PET with autopsy findings. Third, we did not search grey literature, such as abstracts from conferences with exception of the interim report from the IDEAS study. Given the limited number of studies included, mostly with small sample sizes, the findings should be further confirmed by large-scale and longitudinal studies to estimate the generalizable conclusion on the utility of amyloid PET. However, the strengths of this review include encompassing recent clinical studies from around the world, providing a global perspective on AD diagnosis and management in the context of the availability of amyloid PET as a diagnostic tool. In addition, whereas the IDEAS study primarily focused on Medicare beneficiaries in the US who are 65 or older and meet AUC, our review also included studies that examined the impact of amyloid-PET on a broader range of individuals including those who are younger ( $<65$ years old) and those who did not meet AUC criteria. This broader inclusion may provide added insights into the clinical value of amyloid PET in more heterogeneous populations. As new AD biomarkers become available in the future, diagnostic pathways for $\mathrm{AD}$ will most likely continue to evolve.

\section{Acknowledgements}

This study was supported by K23AG043504 (NIA/NIH) (E.O.), R01AG057725 (NIA/NIH) (E.0.), and the Roberts Gift Fund (E.O.). We are also grateful to Carrie Price, Clinical Informationist at the William H. Welch Medical Library, the Johns Hopkins University School of Medicine, for her assistance with literature search. We would also like to thank Dr. Jeannie-Marie Leoutsakos for statistical consultation and Alexandra Pletnikova for editorial assistance.

\section{Disclosure Statement}

The authors have no conflicts of interest to disclose. 


\section{References}

1 Alzheimer's Association: 2018 Alzheimer's disease facts and figures. Alzheimers Dement. 2018;14(3):367429.

2 Kochanek KD, Murphy SL, Xu J, Tejada-Vera B. Deaths: final Data for 2014. Natl Vital Stat Rep. 2016 Jun;65(4): 1-122.

3 Sperling RA, Jack CR Jr, Aisen PS. Testing the right target and right drug at the right stage. Sci Transl Med. 2011 Nov;3(111):111cm33.

4 McKhann GM, Knopman DS, Chertkow H, Hyman BT, Jack CR Jr, Kawas CH, et al. The diagnosis of dementia due to Alzheimer's disease: recommendations from the National Institute on Aging-Alzheimer's Association workgroups on diagnostic guidelines for Alzheimer's disease. Alzheimers Dement. 2011 May;7(3):263-9.

5 Hampel H, Frank R, Broich K, Teipel SJ, Katz RG, Hardy J, et al. Biomarkers for Alzheimer's disease: academic, industry and regulatory perspectives. Nat Rev Drug Discov. 2010 Jul;9(7):560-74.

6 Klunk WE, Engler H, Nordberg A, Wang Y, Blomqvist G, Holt DP, et al. Imaging brain amyloid in Alzheimer's disease with Pittsburgh Compound-B. Ann Neurol. 2004 Mar;55(3):306-19.

7 Sánchez-Juan P, Ghosh PM, Hagen J, Gesierich B, Henry M, Grinberg LT, et al. Practical utility of amyloid and FDG-PET in an academic dementia center. Neurology. 2014 Jan;82(3):230-8.

8 Blennow K, Mattsson N, Schöll M, Hansson 0, Zetterberg H. Amyloid biomarkers in Alzheimer's disease. Trends Pharmacol Sci. 2015 May;36(5):297-309.

9 Mallik A, Drzezga A, Minoshima S. Clinical Amyloid Imaging. Semin Nucl Med. 2017 Jan;47(1):31-43.

10 Boccardi M, Altomare D, Ferrari C, Festari C, Guerra UP, Paghera B, et al.; Incremental Diagnostic Value of Amyloid PET With [18F]-Florbetapir (INDIA-FBP) Working Group. Assessment of the Incremental Diagnostic Value of Florbetapir F 18 Imaging in Patients With Cognitive Impairment: The Incremental Diagnostic Value of Amyloid PET With [18F]-Florbetapir (INDIA-FBP) Study. JAMA Neurol. 2016 Dec;73(12):1417-24.

11 Johnson KA, Minoshima S, Bohnen NI, Donohoe KJ, Foster NL, Herscovitch P, et al.; Alzheimer's Association; Society of Nuclear Medicine and Molecular Imaging; Amyloid Imaging Taskforce. Appropriate use criteria for amyloid PET: a report of the Amyloid Imaging Task Force, the Society of Nuclear Medicine and Molecular Imaging, and the Alzheimer's Association. Alzheimers Dement. 2013 Jan;9(1):e-1-16.

12 Centers for Medicare \& Medicaid Services. Decision memo for beta amyloid positron emission tomography in dementia and neurodegenerative disease (CAG-00431N). Baltimore, Centers for Medicare \& Medicaid Services, 2013.

13 Imaging Dementia-Evidence for Amyloid Scanning (IDEAS) Study. 2015. https://ClinicalTrials.gov/show/ NCT02420756.

14 Apostolova LG, Haider JM, Goukasian N, Rabinovici GD, Chételat G, Ringman JM, et al. Critical review of the Appropriate Use Criteria for amyloid imaging: effect on diagnosis and patient care. Alzheimers Dement (Amst). 2016 Dec;5:15-22.

15 Mitsis EM, Bender HA, Kostakoglu L, Machac J, Martin J, Woehr JL, et al. A consecutive case series experience with [18 F] florbetapir PET imaging in an urban dementia center: impact on quality of life, decision making, and disposition. Mol Neurodegener. 2014 Feb;9(1):10.

16 Carswell CJ, Win Z, Muckle K, Kennedy A, Waldman A, Dawe G, et al. Clinical utility of amyloid PET imaging with (18)F-florbetapir: a retrospective study of 100 patients. J Neurol Neurosurg Psychiatry. 2017;jnnp-2017316194.

17 Weston PS, Paterson RW, Dickson J, Barnes A, Bomanji JB, Kayani I, et al. Diagnosing Dementia in the Clinical Setting: Can Amyloid PET Provide Additional Value Over Cerebrospinal Fluid? J Alzheimers Dis. 2016 Oct; 54(4):1297-302.

18 Ossenkoppele R, Prins ND, Pijnenburg YA, Lemstra AW, van der Flier WM, Adriaanse SF, et al. Impact of molecular imaging on the diagnostic process in a memory clinic. Alzheimers Dement. 2013 Jul; 9(4):414-21.

19 Zwan MD, Bouwman FH, Konijnenberg E, van der Flier WM, Lammertsma AA, Verhey FR, et al. Diagnostic impact of [18F]flutemetamol PET in early-onset dementia. Alzheimers Res Ther. 2017 Jan;9(1):2.

20 Bensaïdane MR, Beauregard JM, Poulin S, Buteau FA, Guimond J, Bergeron D, et al. Clinical Utility of Amyloid PET Imaging in the Differential Diagnosis of Atypical Dementias and Its Impact on Caregivers. J Alzheimers Dis. 2016 Apr;52(4):1251-62.

21 Ceccaldi M, Jonveaux T, Verger A, Krolak-Salmon P, Houzard C, Godefroy O, et al. Added value of 18F-florbetaben amyloid PET in the diagnostic workup of most complex patients with dementia in France: A naturalistic study. Alzheimers Dement. 2017. https://doi.org/10.1016/j.jalz.2017.06.394.

22 Brendel M, Schnabel J, Schönecker S, Wagner L, Brendel E, Meyer-Wilmes J, et al. Additive value of amyloidPET in routine cases of clinical dementia work-up after FDG-PET. Eur J Nucl Med Mol Imaging. 2017 Dec; 44(13):2239-48.

23 Schipke CG, Peters O, Heuser I, Grimmer T, Sabbagh MN, Sabri O, et al. Impact of beta-amyloid-specific florbetaben PET imaging on confidence in early diagnosis of Alzheimer's disease. Dement Geriatr Cogn Disord. 2012; 33(6):416-22.

24 Pontecorvo MJ, Siderowf A, Dubois B, Doraiswamy PM, Frisoni GB, Grundman M, et al. Effectiveness of Florbetapir PET Imaging in Changing Patient Management. Dement Geriatr Cogn Disord. 2017;44(3-4):129-43. 
Kim et al.: Utility of Amyloid PET Imaging

25 Frederiksen KS, Hasselbalch SG, Hejl AM, Law I, Højgaard L, Waldemar G. Added Diagnostic Value of (11)C-PiBPET in Memory Clinic Patients with Uncertain Diagnosis. Dement Geriatr Cogn Disord Extra. 2012 Jan;2(1): 610-21.

26 Grundman M, Pontecorvo MJ, Salloway SP, Doraiswamy PM, Fleisher AS, Sadowsky CH, et al.; 45-A17 Study Group. Potential impact of amyloid imaging on diagnosis and intended management in patients with progressive cognitive decline. Alzheimer Dis Assoc Disord. 2013 Jan-Mar;27(1):4-15.

27 Grundman M, Johnson KA, Lu M, Siderowf A, Dell'Agnello G, Arora AK, et al.; 18F-AV-45-A17 Study Group. Effect of Amyloid Imaging on the Diagnosis and Management of Patients with Cognitive Decline: Impact of Appropriate Use Criteria. Dement Geriatr Cogn Disord. 2016;41(1-2):80-92.

28 Rabinovici GD, Gatsonis C, Apgar C, Gareen IF, Hanna L, Hendrix J, et al. IMPACT OF AMYLOID PET ON PATIENT MANAGEMENT: EARLY RESULTS FROM THE IDEAS STUDY. Alzheimers Dement. 2017;13(7):1474.

29 Huijbers W, Mormino EC, Schultz AP, Wigman S, Ward AM, Larvie M, et al. Amyloid- $\beta$ deposition in mild cognitive impairment is associated with increased hippocampal activity, atrophy and clinical progression. Brain. 2015 Apr;138(Pt 4):1023-35.

30 Wahlster P, Niederländer C, Kriza C, Schaller S, Kolominsky-Rabas PL. Clinical assessment of amyloid imaging in Alzheimer's disease: a systematic review of the literature. Dement Geriatr Cogn Disord. 2013;36(5-6):26378.

31 Hatashita S, Wakebe D. Amyloid- $\beta$ Deposition and Long-Term Progression in Mild Cognitive Impairment due to Alzheimer's Disease Defined with Amyloid PET Imaging. J Alzheimers Dis. 2017;57(3):765-73.

32 Rinne JO, Brooks DJ, Rossor MN, Fox NC, Bullock R, Klunk WE, et al. 11C-PiB PET assessment of change in fibrillar amyloid-beta load in patients with Alzheimer's disease treated with bapineuzumab: a phase 2, doubleblind, placebo-controlled, ascending-dose study. Lancet Neurol. 2010 Apr;9(4):363-72.

33 Zannas AS, Wong TZ, Doraiswamy PM. How much is a picture worth? Putting amyloid imaging to the test. Dement Geriatr Cogn Disord Extra. 2012 Jan;2(1):649-51.

34 Arciniegas DB, Anderson CA. Donepezil-induced confusional state in a patient with autopsy-proven behavioral-variant frontotemporal dementia. J Neuropsychiatry Clin Neurosci. 2013;25(3):E25-6.

35 Boxer AL, Knopman DS, Kaufer DI, Grossman M, Onyike C, Graf-Radford N, et al. Memantine in patients with frontotemporal lobar degeneration: a multicentre, randomised, double-blind, placebo-controlled trial. Lancet Neurol. 2013 Feb;12(2):149-56.

36 Mendez MF, Shapira JS, McMurtray A, Licht E. Preliminary findings: behavioral worsening on donepezil in patients with frontotemporal dementia. Am J Geriatr Psychiatry. 2007 Jan;15(1):84-7. 